\title{
A detergent for mango fruit sap-induced injury
}

\begin{abstract}
This study determined the optimum concentration of, and duration of immersion in a local detergent ("awabla") that protected fruit skin of Kent and Keitt mango varieties from mango fruit sap-induced injury (sap-burn) at harvest.The resultant skin/peel colour, pulp colour, and total soluble solids content was also evaluated for fruit quality. Randomized Complete Block Design and Completely Randomized Design with four replications in each case were used for field and laboratory experiments respectively. For each of the two varieties, ten mango trees were sampled at random in each of the four replications of a mango plantation. On each sample tree, twenty panicles all initiating fruit-set were identified and tagged. The number of days from fruit-set to physiological maturity were monitored and harvested for the experiments. Concentrations of $0.25,0.50$, and $0.75 \%$ of "awabla" solution for 25,30 ,and 35 minutes immersion period in all combinations were established as appropriate and recommended for management of Kent and Keitt mango fruit sap-induced injury. The detergent ("awabla") had a proven efficacy in the range of 87-94 \% for Kent and 90-93\% for Keitt. The resultant peel colour, pulp colour, and total soluble solids content of Kent and Keitt mango fruit samples were not significantly influenced by the treatments at $p>0.05$.
\end{abstract}

\author{
Volume 5 Issue 5 - 202I
}

\author{
Moomin Abu,' Eric Mwinlanaa Yuoni² \\ 'Department of Horticulture, Faculty of Agriculture, Food \\ and Consumer Sciences, University for Development Studies, \\ Tamale, Ghana \\ ${ }^{2}$ Departmentof Agricultural Mechanization and Irrigation \\ Technology, Faculty of Agriculture, Food and Consumer \\ Sciences, University for Development Studies, Tamale, Ghana
}

Correspondence: Department of Horticulture, Faculty of Agriculture, Food and Consumer Sciences, University for Development Studies, Tamale, Ghana, Tel +233244849469, Emailmoonabu@yahoo.com

Received: November 05, 2021 | Published: December 23, 2021

Keywords: detergent, efficacy, mango fruit, mango sap, sap-induced injury

\section{Introduction}

Fruits and vegetables are inevitably a necessity since their relevance to mankind is related to their nutritional value as main sources of vitamins and minerals that ensure a balanced diet. ${ }^{1,2}$ Agricultural Transformation Agency (ATA) demonstrated a universal recognition that fruits and vegetables were important foods and that their production, processing, and marketing were significant contributors to household food security and income. ${ }^{3}$ This source indicated that fruits and vegetables comprised a large portion of human diet and in most cases the only form of relish for the low-income group. Fruits and vegetables also provide dietary fibre which enhances digestion and improves the health of mankind. ${ }^{3}$ Fruits and vegetables also contribute substantially to the gross domestic product. Unfortunately, the magnitude of postharvest losses in fresh fruits and vegetables was estimated to be 5 to 25 percent in developed countries and 20 to 50 percent in developing countries depending on the commodity. $4,5,6,7$

Estimates of loss magnitudes in developing countries for fruits and vegetables indicated very wide ranges for specific crops e.g. losses of tomato fruit varied from 20-50 \%; banana, 20-80\%; and papaya, $40-100 \% .{ }^{6,7}$ For fruits and vegetables produced in Ghana, 5-40 \% was lost during the various stages of the marketing process i.e. at every step from harvest to retail and sale. ${ }^{8,9,10}$ Narrowing down to specific crops in Ghana, it was estimated that e.g. losses of tomato fruits were in the range of 30-70 \%; and mango, 50-80\%. ${ }^{11,9}$ But the aim of postharvest studies is to reduce losses and to do so, the way forward is to understand the biological factors involved in deterioration, the environmental factors that influence deterioration, and use those postharvest technology procedures which will delay senescence and maintain the best possible quality. Abu et al. ${ }^{12}$ reiterated that reduction in losses resulted in low cost of production, improved trade and distribution, enhanced food security especially in developing countries, lowered the price for consumers and at the same time increased farmers' income.

During the developmental or growth period of fruits there are many chemical and physical changes taking place that have a bearing on fruit quality ad postharvest behaviour. Fruits are highly perishable products and their quality could be affected by both harvest and postharvest practices such as method and condition of harvest, handling, transportation, storage, and marketing. ${ }^{6,7,9}$ Losses could also occur in fruits via the natural physiological constitution of the plant species such as the ability or otherwise the inherent characteristic of the species for exuding latex (mango fruit sap) at harvest which is unavoidable in mango production. Yuoni ${ }^{13}$ reported that when mango fruit sap (latex)came into contact with the mango fruit peel it resulted in sap burn injury. The author however added that the susceptibility of mango fruit to sap-induced injury as well as the severity of the injury variedwith the cultivar.

Porat et al., ${ }^{6}$ Yahaya et al. ${ }^{7}$ and Abu et al. ${ }^{14}$ reported that latexflow from harvested mango fruit occurred even after physiological maturity (pre-climacteric stage -the stage of development when most commercial harvests take place) at a decreasing rate. Latex-flow persisted up to packaging. ${ }^{14}$

Yuoni ${ }^{13}$ and Abu et al. ${ }^{14}$ indicated that the sap, which is sticky in nature, caused browning, hardened, and stained the skin of the fruit contacted. The affected skin area sub sequently became site for secondary infection, degraded the aesthetic appeal of the fruit, reduced consumer acceptability, decreased the value and storage life of the fruit, and therefore resulted in quantitative and qualitative losses. These losses were manifested in several ways including weight loss (quantitative), quality loss (qualitative), nutritional loss (food value), seed loss (viability or germination), economic loss (monetary), loss of good will (reputation), and loss of marketing opportunities for the farmer, the seller, and the consumer alike. ${ }^{13,15}$ Saeed ${ }^{5}$ earlier on reiterated that these impacted negatively on food security and nutrition. The author added that successful production i.e. production characterized with meagre losses could enhance subsistence, incomegeneration, and even export in the developing world.

Krishnapillai et al. ${ }^{16}$ reported that the concentration of tannins decreased with maturity as a result of polymerization which is associated with the disappearance of latex. According to Abu et al. ${ }^{14}$ phenolics such as tannins and perhaps the most important phenolics from the point of view of fruit utilization are polymerized to insoluble 
compounds resulting in a reduction of astringency during ripening. This seems to be associated with a change in structure of the tannins rather than a reduction in the levels since they form polymers. ${ }^{14}$ In mango fruit, however, latex-flow does not stop entirely after harvest at physiological maturity stage but reduces in flow rate and quantity along the harvest and pack-house processes with time. ${ }^{14}$ On-tree ripe mango fruits, however, showed complete disappearance of latex-flow or exudation at harvest. These fruits also developed better quality in flavour and colour, though undesirable in some respects since such fruits were more susceptible to spoilage by birds and other rodents and also did not keep long in storage, and hence in transit. ${ }^{17,18}$ Parthasarathy ${ }^{19}$ noted that mango fruits that secreted little to no latex at harvest enhanced fruit acceptability and also allowed for easier fruit handling since the latex was corrosive and damaged the fruit skin and as well caused irritation on human skin when in contact.

Several methods have been used to manage sap burn injury in mangoes ${ }^{19-23}$ but with the inclusion of chemicals which might have been sophisticated, expensive, and which certainly provided a quick fix but were ultimately self-defeating. ${ }^{18,24}$ In the same vein Krishnapillai et al. ${ }^{16}$ indicated that simple, inexpensive, and environmentally friendly methods could be used to reduce sap burn injury in mangoes.

Mango farmers made frantic efforts for any harvest technique(s) worthy of adoption that could aid avert the consequences of mango fruit sap-induced injury. ${ }^{14}$ Nevertheless, while highly recommended, any precautionary measures may be inadequate and even fruitless if a simple inexpensive de-sapping technique or practice is not known to the mango farming and beneficiary communities. Hence, the need to investigate into and ascertain the efficacy of "awabla" for the purpose.

The objectives were: to determine the appropriate concentration of "awabla" solution for optimum protection of mango fruit from sap burn injury, to determine the appropriated uration for which freshly harvested mango fruits would be immersed in "awabla" solution for optimum protection of mango fruit from sap burn injury, to evaluate the resultant skin/peel colour, pulp colour, and total soluble solids(TSS)content for fruit quality.

\section{Materials and methods}

\section{Experimental site and plant materials}

Field and laboratory studies were conducted at the Integrated Tamale Fruit Company (ITFC) Ltd nucleus Mango Plantation in Dipale and at the Bio-chemistry Laboratory, Spanish Laboratory, University for Development Studies, Tamale, Ghana, respectively. The study investigated and ascertained the efficacy of "awabla" (a local detergent) solution for optimum protection of Kent and Keitt mango fruit from mango sap burn injury consequences. Kent and Keitt are major export mango varieties which are appreciated by importers of mango from Ghana. ${ }^{25,26,15}$ Dipale is a farming community in the north-western part of Savelugu District in the Northern Region of Ghana.Randomized Complete Block Design (RCBD) and Completely Randomised Design (CRD) were used for the field and laboratory experiments respectively, with four replications in each case.

\section{Field studies}

\section{Sampling and harvesting of fruits for experimentation}

For each of the two varieties, ten mango trees were sampled at random in each of the four replications. On each sample tree, twenty panicles all initiating fruit-set were identified and tagged i.e. date of fruit-set initiation was noted and recorded for each sample tree. The number of days from fruit-set to physiological maturity (green-hard, outgrown shoulders, pit around the stalk-end, and turning yellow or showing an apparent break of yellow colour in the pulp/flesh characteristic of Kent and Keitt) i.e. at early maturity (pre-climacteric stage) for Kent and Keitt (126 and 140 days respectively) were monitored and harvested for the experiments. ${ }^{15}$ The authors indicated that the number of days from fruit-set to harvest provide one of the best and reliable indicators of maturity (early, mid or late harvest) and represents the optimum age of the fruit for quality postharvest behaviour.

\section{Composition, different concentrations, and immersion regimes tested}

Oyekanmi et.al. ${ }^{20}$ and Yuoni ${ }^{13}$ reported that "awabla" was a composition of $10 \%$ moisture, $0.1 \%$ alkaline, $5 \%$ unsaponified neutral fat, $55 \%$ total fatty matter, a bulk density of $2 \%, 4 \%$ matter insoluble inwater, $5 \%$ matter insoluble in ethanol, and a titre value of $58 \%$. Four different concentration (\%) levels $\{0.00 \%$ (control), 0.25 $\%, 0.50 \%$, and $0.75 \%$ of "awabla"solution and three immersion regimes (minutes) $(35,30$, and 25 minutes) were used, following recommendations of Yuoni. ${ }^{13}$ Yuoni ${ }^{13}$ indicated that "awabla" is prepared from Amaranthus spinosus(Spiny Amaranth) which possesses anti-microbial properties. ${ }^{27}$

\section{Definition of treatments}

Concentration one $=\mathrm{C} 1=0.25 \%$
Concentration two $=\mathrm{C} 2=0.50 \%$
Concentration three $=\mathrm{C} 3=0.75 \%$
Control = no "awabla" $=\mathrm{C} 0=0.00 \%$
Immersion period one $=\mathrm{T} 1=\mathrm{T} 35=35$ minutes
Immersion period two $=\mathrm{T} 2=\mathrm{T} 30=30$ minutes
Immersion period three $=\mathrm{T} 3=\mathrm{T} 25=25$ minutes.

\section{Treatments}
$\mathrm{C} 1 \mathrm{~T} 35=$ Concentration of $0.25 \%$ for 35 minutes
$\mathrm{C} 1 \mathrm{~T} 30=$ Concentration of $0.25 \%$ for 30 minutes
$\mathrm{C} 1 \mathrm{~T} 25=$ Concentration of $0.25 \%$ for 25 minutes
$\mathrm{C} 2 \mathrm{~T} 35=$ Concentration of $0.50 \%$ for 35 minutes
$\mathrm{C} 2 \mathrm{~T} 30=$ Concentration of $0.50 \%$ for 30 minutes
$\mathrm{C} 2 \mathrm{~T} 25=$ Concentration of $0.50 \%$ for 25 minutes
C3T $35=$ Concentration of $0.75 \%$ for 35 minutes
$\mathrm{C} 3 \mathrm{~T} 30=$ Concentration of $0.75 \%$ for 30 minutes
$\mathrm{C} 3 \mathrm{~T} 25=$ Concentration of $0.75 \%$ for 25 minutes
$\mathrm{C} 0 \mathrm{~T} 35=$ no "awabla" for 35 minutes
$\mathrm{C} 0 \mathrm{~T} 30=$ no "awabla" for 30 minutes
$\mathrm{C} 0 \mathrm{~T} 25$ = no "awabla" for 25 minutes.

\section{Laboratory studies}

Application of treatments (de-sapping of mango fruits) and storage of treated fruit samples for sap burn injury determination

Ten fruits were randomly picked for each treatment in each of the four replications in each case of the two varieties. Sample fruits with pedicel length $1 \mathrm{~cm}^{9,15,14}$ were treated as outlined above under 
subtitle "treatments". Treated samples were accordingly stored in cardboard boxes under ambient conditions $\left(29-31{ }^{\circ} \mathrm{C}, 90-95 \% \mathrm{RH}\right)^{9}$ for seven days ${ }^{15}$ and assessed for sap burn injury consequences viz. skin/peel colour, pulp colour, and TSS content. Sap burn injuries were highlighted and the area of the injury calculated by multiplying the length by the breadth $(\mathrm{L} \mathrm{xB})$ in centimeters $(\mathrm{cm})$ for each fruit.The injury area defined over the seven days storage period was calculated and averaged for each treatment in each of the four replications in each case of the two varieties. The figure obtained represented the injury area defined on the fruit in a particular treatment over the storage period. ${ }^{28}$

The extent of injury on the fruit in relation to any treatment was scored on the scale $0-4$.

$$
\begin{aligned}
& 0=\text { no injury, } \\
& 1=\text { very mild (injury area less than } 1 \mathrm{~cm}^{2} \text { ), } \\
& 2=\text { mild (injury area }>1<2 \mathrm{~cm}^{2} \text { ), } \\
& 3=\text { moderate (injury area }>2<4 \mathrm{~cm}^{2} \text { ), } \\
& 4=\text { severe (injury area }>4 \mathrm{~cm}^{2} \text { ). }
\end{aligned}
$$

Values were recorded for each of the ten fruits and averaged for each treatment.

NB: Those with least score values were of better quality (with regards to sap burn injury) than those with higher score values.

\section{Physicochemical analyses}

Physico-chemical analyses on mango skin/peel colour, consistency of mango pulp, and total soluble solids (TSS, ${ }^{\circ} \mathrm{Brix}$ ) content of mango were done on fruits at physiological maturity or at pre-climacteric stage (green-hard, outgrown shoulders, pit around the stalk-end, skins of many fruits develop wax - giving the fruit a shine or bloom, and showing an apparent break of yellow colour in the pulp). ${ }^{29,30,15}$

Determination of fruit total soluble solids (TSS, ${ }^{\circ}$ Brix) content was by the $\mathrm{AOAC}^{31}$ procedures whiles that of fruit skin colour and consistency of pulp were by the SAMGA ${ }^{32}$ procedures. These were done at the early harvest stages obtained by the age control criterion because of its precision in measuring or determining harvest maturity stage. . $9,30,15^{-15}$

\section{Statistical analyses}

All data were analysed using the Analysis of Variance (ANOVA) technique ${ }^{33}$ with the GENSTAT statistical program. Least Significant Difference (LSD) at $5 \%$ probability level was used to determine treatment differences.

\section{Results}

Sap burn injury scores, fruit pulp colour consistency, skin/peel colour mean scores, and total soluble solids (TSS) content in relation to treatments applied to kent fruit samples

\section{Sap burn injury scores in relation to treatment}

Untreated Kent fruit samples (C0T35, C0T30, and C0T25) showed comparatively high sap burn injury (sap burn injury mean scores of $1.87,1.80$, and 1.80 for $\mathrm{C} 0 \mathrm{~T} 35, \mathrm{C} 0 \mathrm{~T} 30$, and $\mathrm{C} 0 \mathrm{~T} 25$ respectively) than the other treatments (Figure 1). Treatments C1T30 and C2T30 gave the lowest sap burn injury with a mean score of 0.07 in each case (Figure 1). Fruits treated with $\mathrm{C} 1 \mathrm{~T} 30$ and $\mathrm{C} 2 \mathrm{~T} 30$ were therefore of optimum quality in relation to sap burn injury though the different sap burn injury mean scores recorded were not significantly different amongst the treatments at $\mathrm{p}>0.05$ (Figure 1).

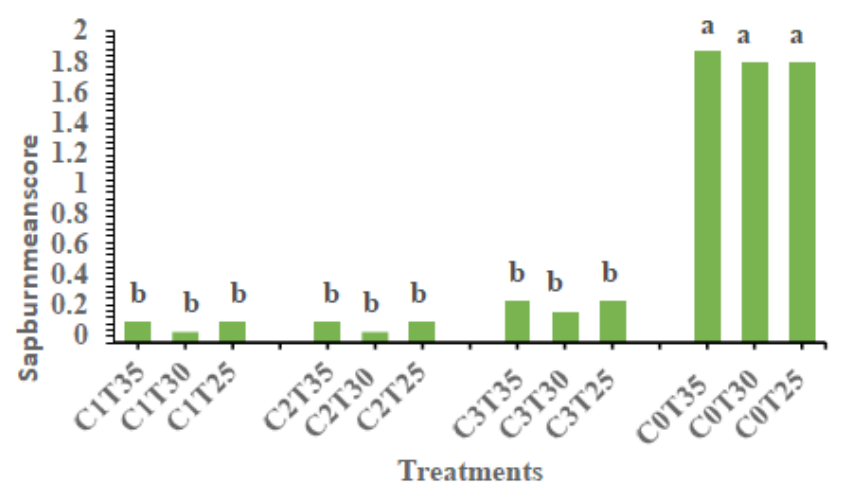

Figure I Sap burn injury scores in relation to treatment.

Mean bars with similar alphabets are not significantly different. Bar values means \pm SEM, $n=3$.

\section{Fruit pulp colour consistency in relation to treatment}

Untreated fruits and those treated with C3T30 and C3T25 showed the most developed pulp colour consistency with a common mean score of 0.6 ,which was the maximum score on the mango pulp colour chart (Figure 2). Treatments C1T35 and C1T25 were least developed in pulp colour consistency with a mean score of 0.57 in each case (Figure 2).

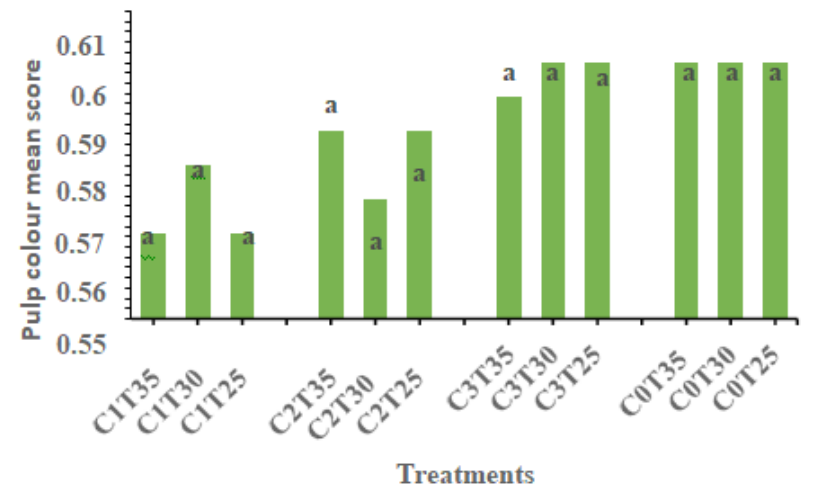

Figure 2 Fruit pulp colour consistency in relation to treatment.

Mean bars with similar alphabets are not significantly different. Bar values means \pm SEM, $n=3$.

\section{Skin colour mean scores in relation to treatment}

Treatment C0T25 showed the most-high mean score of 6.0 for Kent fruit skin colour development over the experimental period while treatment C3T35 recorded 5.08 which was the most-low mean score for peel colour development (Figure 3). Generally, all the treatment recorded fairly high mean scores for skin colour development but there were no significant differences amongst the mat $\mathrm{p}>0.05$ (Figure $3)$.

\section{Total soluble solids (TSS) content in relation to treatment}

The highest TSS mean score value of 20.27 w a s recorded for treatment C0T25 over the experimental period whiles a mean score value of 18.33 was recorded for treatment C3T35, and was the least amongst the Kent treatments (Figure 4). There were no significant differences among treatment means at $\mathrm{p}>0.05$ (Figure 4). Sap Burn 
Injury Scores, Fruit Pulp Colour Consistency, Skin/Peel Colour Mean Scores, and Total Soluble Solids (TSS) Content in relation to Treatments Applied to Keitt Fruit Samples.

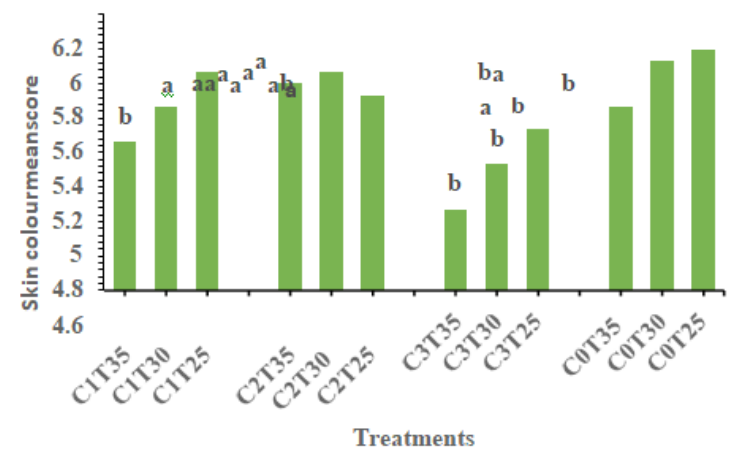

Figure 3 Skin colour mean scores in relation to treatment.

Mean bars with similar alphabets are not significantly different. Bar values means \pm SEM, $n=3$.

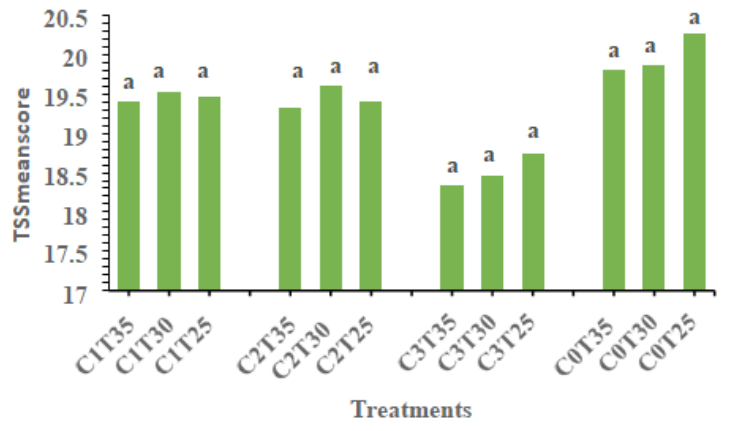

Figure 4 Total soluble solids (TSS) content in relation to treatment.

Mean bars with similar alphabets are not significantly different. Bar values means \pm SEM, $n=3$.

\section{Sap burn injury scores in relation to treatment}

Significantly $(\mathrm{p}<0.05)$ high sap burn injury scores of $1.73,1.66$, and 1.80 were recorded for treatments C0T35, C0T30, and C0T25 respectively while the most low sap burn injury mean score of 0.07 was recorded for treatment C2T30 of the Keitt fruit samples (Figure 5). There were however no significant $(\mathrm{p}>0.05)$ differences in the strength of sap burn injury among treatments C1T35, C1T30, C1T25, C2T35, C2T30, C2T25, C3T35, C3T30, and C3T25 (Figure 5).

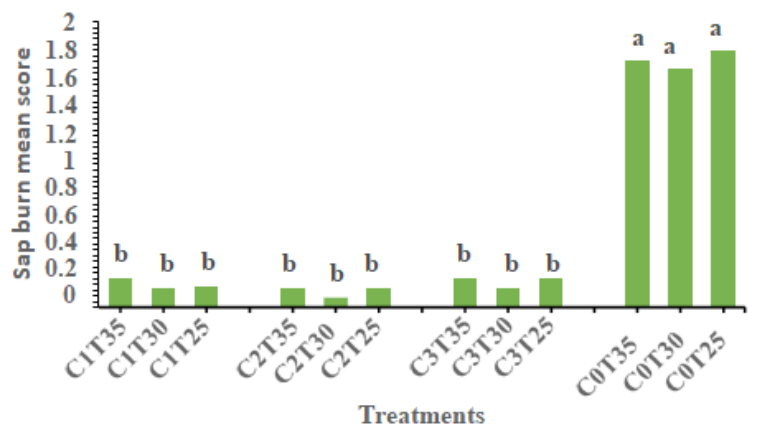

Figure 5 Sap burn injury scores in relation to treatment.

Mean bars with similar alphabets are not significantly different. Bar values means \pm SEM, $n=3$.

\section{Fruit pulp colour consistency in relation to treatment}

Treatment C3T25 recorded the most-high pulp colour consistency mean score of 0.58 while treatment C1T25 recorded the least $(0.36)$
(Figure 6). Pulp colour development for all the treatments was generally consistent except for treatments with $0.25 \%$ detergent concentration labels whose mean scores were apparently low as compared to the other treatments (Figure 6). The results also showed that fruit pulp colour consistency increased with increased concentration of the detergent for the Keitt fruit samples (Figure 6).

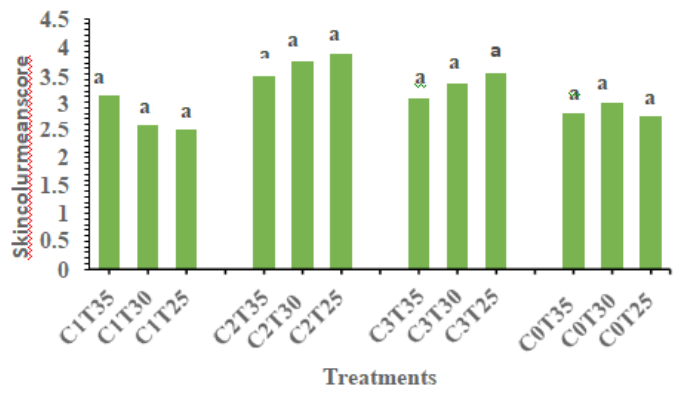

Figure 6 Fruit pulp colour consistency in relation to treatment.

Mean bars with similar alphabets are not significantly different. Bar values means $\pm \mathrm{SEM}, n=3$.

\section{Peel colour mean scores in relation to treatment}

Peel colour development mean score of 3.87 for treatment C2T25 was the most-high over the experimental period while treatment C1T25 recorded the most-low mean score of 2.50 (Figure 7). Peel colour development was fairly uniform amongst the various treatments (Figure 7).

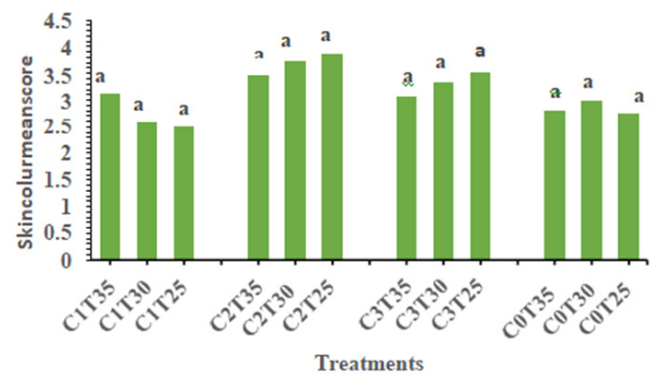

Figure 7 Peel colour mean scores in relation to treatment.

Mean bars with similar alphabets are not significantly different. Bar values means \pm SEM, $n=3$.

\section{Total soluble solids (TSS) content in relation to treatment}

Treatment C3T25 recorded the most-high TSS content mean score of 19.40 whiles treatment C1T25 recorded the least (16.95) (Figure $8)$. There were however no significant differences among treatment means at $\mathrm{p}>0.05$ (Figure 8 ).

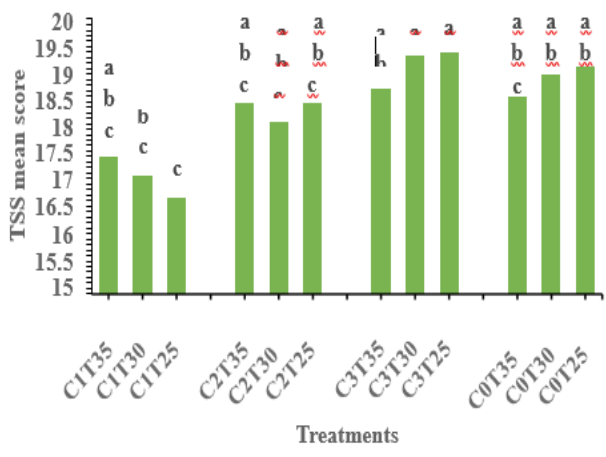

Figure 8 Total soluble solids (TSS) content in relation to treatment.

Mean bars with similar alphabets are not significantly different. Bar values Means \pm SEM, $n=3$. 


\section{Discussion}

Sap burn injury scores, fruit pulp colour consistency, skin/peel colour mean scores, and total soluble solids (TSS) content in relation to treatments applied to kent and keitt mango fruit samples

Karunanayake, ${ }^{34}$ Krishnapillai and Wijeratham, ${ }^{16}$ and Saby John et $\mathrm{al}^{35}$ indicated that mango sap is highly acidic in nature with a $\mathrm{pH}$ of 4.3 and therefore injures/ scorches the fruit skin/peel when in contact, thus rendering the fruit unappealing/unsightly. According to Barman et al., ${ }^{21}$ the onset and severity of mango sap burn injury increased up to ripening during storage at ambient temperatures.

For Kent mango fruit samples, sap-induced injury levels were managed to an average of $6 \%$ by the $0.25 \%$ concentration of "awabla" solution for the three different durations of immersion, $6 \%$ by the $0.50 \%$ concentration of "awabla" solution for the three different durations of immersion, and $13 \%$ by the $0.75 \%$ concentration of "awabla" solution for the three different durations of immersion; all as a percentage of sap burn injury recorded for the Control in each case. In the case of Keitt mango fruit samples sapinduced injury levels were managed to an average of $9 \%$ by the 0.25 $\%$ concentration of "awabla" solution for the three different durations of immersion, $7 \%$ by the $0.50 \%$ concentration of "awabla" solution for the three different durations of immersion, and $10 \%$ by the 0.75 $\%$ concentration of "awabla" solution for the three different durations of immersion; again, all as a percentage of sap burn injury recorded for the Control in each case. Therefore, the detergent ("awabla") had a proven efficacy in the range of 87-94 \% for Kent and 90-93\% for Keitt. This meant that out of the samples in the trials, those that received treatment (treated) were at a range of 87-94\% lower risk of developing sap burn injury in the case of Kent and 90-93\% in the case of Keitt. In both cases of Kent and Keitt fruit samples, sap burn injury levels of the untreated samples were significantly higher than those of the treated samples at $p<0.05$. Thus, both Kent and Keitt fruits that were treated with the local detergent at various concentrations showed significantly $(\mathrm{p}<0.05)$ low sap burn injury levels compared to the control (untreated); indicating that the detergent was able to manage sap burn injury up to eat-ripe stage in storage. Abu et al. ${ }^{15}$ indicated that fruits of Haden, Kent, Palmer, and Keitt mango varieties attained eat-ripe stage maturity from physiological maturity after seven days in storage under ambient conditions.

According to Ikotunetal. ${ }^{23}$ an African black soap that was prepared from shea butter and cocoa pods was found to be more of an alkaline base with a $\mathrm{pH}$ value of 9.56. The application of this local detergent counteracted the effect of the acidity of mango fruit sap and protected the fruits from sap burn injury. For Kent mango fruit samples, treatments $\mathrm{C} 1 \mathrm{~T} 30$ and $\mathrm{C} 2 \mathrm{~T} 30$ gave the lowest sap burn injury with a mean score of 0.07 in each case while the most-low sap burn injury mean score of 0.07 was recorded for treatment C2T30 of the Keitt mango fruit samples. These suggested that Kent fruits treated with C1T30 and C2T30 and Keitt fruits treated with C2T30 were of preponderance in optimum quality in relation to sap burn injury even though the different sap burn injury mean scores recorded, other than those of the control, were not significantly different from one another at $\mathrm{p}>0.05$. Hence, the statement by Krishnapillai et al. ${ }^{16}$ that low cost environmentally friendly methods could be used to manage mango fruit sap-induced injury.

Over the experimental period pulp colour of all the Kent and Keitt mango fruit treatments developed to levels that were not significantly different at $\mathrm{p}>0.05$. For Kent fruits, the control treatments and treatments $\mathrm{C} 3 \mathrm{~T} 30$ and $\mathrm{C} 3 \mathrm{~T} 25$ recorded a mean score of 0.6 which was the highest though treatments C1T25 and C1T35 recorded the least mean score of 0.57 which was not significantly different from the former at $p>0.05$. With Keitt fruits, pulp colour development for all the samples was generally consistent except for samples treated with $0.25 \%$ detergent concentration whose mean scores were comparatively low. These suggested that the detergent did not influence the development of pulp colour over the experimental period. According to Parthasarathy, ${ }^{19}$ Oyekanmi et al., ${ }^{20}$ and Krishnapillai and Wijeratham ${ }^{16}$ mango fruits that were treated with a detergent for sap burn injury management resulted in no significant differences $(\mathrm{p}>0.05)$ in $\mathrm{pH}$, TSS, and pulp colour/consistency among treatments in both the non-treated and treated fruits.

Altendorf ${ }^{36}$ and Tharanathan et al. ${ }^{37}$ reported that optimum skin/peel colour was an important mango fruit quality parameter that affected consumer acceptance and preference. Generally, all the treatments recorded fairly high mean scores for skin colour development in the present study but there were no significant differences $(p>0.05)$ amongst them; an indication that the detergent did not influence peel colour development over the experimental period.

Amin et al. ${ }^{28}$ evaluated the performance of lime $\{\mathrm{Ca}(\mathrm{OH}) 2\}$ at different times of the day in comparison with Australian industry product \{"Mango Wash"\} for some physico-chemical attributes of mango fruit including fruit peel colour and non-reducing sugar content. Both lime and Mango Wash treatments showed significantly less sap injury when compared to control for all the three times \{morning(7a.m.), noon(12 p.m.), and evening(5p.m.) and subjected to lime $(0.5 \%)$ and Mango Wash at $(0.4 \%)$ treatments $\}$ of treatment application. No sap injury ( 0 score) was observed in the fruits harvested and de-sapped during morning where as maximum sap injury was observed a noon in both the cases $(0.5$ score for lime, 0.75 score for Mango Wash). In the same vein significantly high Total Soluble Solids value was recorded for fruit harvested at noon when compared to other times of the day. ${ }^{28}$

Almost all the physico-chemical attributes were not significantly affected by the de-sapping treatments. Fruit peel colour was slightly suppressed by Mango Wash. Lime was found to give an attractive appearance to the fruits; however, the skin colour was not significantly improved when compared to the control. The time of fruit harvest also indicated non-significant effects on most of the fruit quality attributes..$^{20,23,28}$

At the end of the storage period, levels of TSS content of all the different treatment samples were not significantly different from one another at $\mathrm{p}>0.05$,suggesting that the detergent did not influence the development of TSS after treatment and storage. Amin et al., ${ }^{28}$ Oyekanmi et al..$^{20}$ and Ikotun et al. ${ }^{23}$ all attested that the quality of all tested physico-chemical attributes ( $\mathrm{pH}, \mathrm{TSS}$, and mark etability) were found not to be significantly affected by de-sapping treatments at $p>0.05$ following their assessment via fruits of different mango ('Willard', 'Chembaddan', and 'Ambalavi' mangoes) varieties.

\section{Conclusion}

Concentrations of $0.25,0.50$, and $0.75 \%$ of "awabla" solution for 25,30 , and 35 minutes immersion period in all combinations were established as appropriate and recommended for management of Kent and Keitt mango fruit sap-induced injury. The detergent ("awabla") had a proven efficacy in the range of 87-94 \% for Kent and 90-93 $\%$ for Keitt. The resultant peel colour, pulp colour, and total soluble solids (TSS) content of Kent and Keitt mango fruit samples were not significantly influenced by the treatments at $\mathrm{p}>0.05$. 


\section{Acknowledgments}

The management of Integrated Tamale Fruit Company (ITFC) Ltd Nucleus Mango Plantation in Dipale, Tamale, Ghana and the management of the Bio-chemistry Laboratory, Spanish Laboratory, University for Development Studies, Tamale, Ghana, are gratefully acknowledged for their co-operation and moral support.

\section{Conflicts of interest}

Authors declare that no conflicts of interest existed.

\section{References}

1. Seidu A. Comparative studies on compound and single-based fertilizers as applied to exotic / minor vegetable crops cultivated in the guinea savannah region of Ghana. MPhil Thesis submitted to the School of Postgraduate Studies, University for Development Studies. Tamale: Ghana; 2018. p. 123.

2. Allan VJ. The extent of organic and inorganic farming practices as adopted by vegetable farmers in the Northern region of Ghana. MSc Thesis submitted to the Graduate School, UDS, Tamale: Ghana; 2018. p. 125 .

3. ATA Agricultural Transformation Agency (ATA) Report on Assessment of Market Linkage Opportunities in Horticultural Vegetable Value Chain. Addis Ababa: Ethiopia; 2014.

4. Kader KA, Kasmire RF, Mitchell FG, et al. Post harvest Technology of Horticultural Crops. Division of Agriculture and Natural Resources. Univ. of California. Davis: CA; 1985. p. 192.

5. Saeed K. Causes of post harvest losses of mango and shea fruits in northern Ghana. Master's dissertation submitted in partial fulfilment of the requirements for the degree of Master of Nutrition and Rural Development. Ghent University. West Africa; 2012. p. 64.

6. Porat R, Lichter A, TerryAL, et al. Postharvest losses of fruit and vegetables during retail and in consumers' homes: Quantifications, causes, and means of prevention, Postharvest Biology and Technology. 2018;139:135-149.

7. Yahaya S M, Mardiyya AY. Review of Post-Harvest Losses of Fruits and Vegetables. Biomed J Sci \&Tech Res. 2019; 2574-1241.

8. Gyiele KN. A Baseline Study of Vegetable Production in Ghana. 1999. p. 133.

9. Abu M, Olympio NS, Darko JO. Effects of different storage temperature conditions on ripening quality and shelf life of mango (Mangifera indica) fruits in Ghana. Journal of Horticulture and Postharvest Research. 2020;3(2): 245-256.

10. Abu M. Effect of compound and single-based fertilizers on shelf life of exotic/minor vegetable crops cultivated for the fresh market. Horticulture International Journal.2020;5(2):90-95.

11. Olympio NS, Ellis WO, Mensah E, et al. Postharvest problems of tomato Production in Ghana - Field Studies of some selected major growing areas in Ghana. Journal of the Ghana Science Association. 1998;1(1):55-59.

12. Abu M, Mohammed IK, Anang BT. Profitability of vegetable marketing in Ghana: The case of urban and semi-urban marketeers in the Upper West Region. International Journal of Innovation and Applied Studies. 2020;31(2),258-266.

13. Yuoni EM. Protection from sap-induced injuryof Kent and Keitt Mango varieties with local detergent ("awabla"). MPhil thesis submitted to the University for development studies, Tamale: Ghana; 2020. p. 97.

14. Abu M, Olympio NS, Darko JO. Determination of Harvest Maturity for Mango (Mangifera indica L.) Fruit by Non-Destructive Criteria. Agricultural Sciences. 2021;12:1103-1118.

15. Abu M, Abbey LD, Amey N K. Relation of harvesting time on physic chemical properties of Haden, Kent, Palmer, and Keitt mango varieties for export and local markets. Journal of Horticulture and Postharvest Research. 2021;4(1):87-100.
16. Krishnapillai N, Wijeratham W R S. Sap burn management of mangoes (Mangifera indica L.) in SriLanka. Pakistan Journal of Botan. 2016;48(5):2147-2152.

17. Mazhar MS, Amin M, Malik UA, et al. Improved harvest and desapping practices affect mango fruit quality along the supply chain. International journal of agriculture and biology. 2011;13(5):776-780.

18. Barman K, Ahmad M S, Siddiqui M W. Factors affecting the quality of fruits and vegetables: Recent understandings. In MW Siddiqui editor. Postharvest biology and technology of horticultural crops: Principles and practices for quality maintenance. Waretown, NJ: Apple Academic Press; 2015. p. $1-50$.

19. Parthasarathy S. Sap-injury in mango and their management. 2014.

20. Oyekanmi Adeyinka M, Adebayo Olukemi R, FarombiAbolaji G. Physiochemical Properties of African Back Soap, and It's Comparison with Industrial Black Soap. American Journal of Chemis. 4(1):35-37.

21. Barman K, Asrey R, Pal RK et al. Influence of different desapping agent son the incidence of sapburn, ripening behaviour and quality of mango. Food science technology. 2015;51(1):161-170.

22. Ahmad MS, Siddiqui MW. Factors Affecting Postharvest Quality of Fresh Fruits. Springer International Publishing, Basel. 2015;7-32.

23. Ikotun A Adebomi, Ogundele O Fisayo, Kayode O Mobolaji. Chemical and Biological Significance of Naturally occurring Additives on African Black Soap and its Performance. Journal of Applied Science and Environmental. Management. 2017;21(7):1370-1373.

24. Zinati G. Variations in Soil Health Indicators as a Result of Cropping Systems and Management Practices in Vegetable Systems. Rodale Institute, Kutztown: PA; 2021. 19530.

25. Zakari AK. Ghana National Mango Study. 2012.

26. Okorley EL, Acheampong L, Abenor MT. The current status of mango farming business in Ghana: A case study of mango farming in the Dangme West District. Journal of Agricultural Science. 2014;47(1):1-2.

27. Choudhary V. Medicinal uses of Spiny Amaranth (Amaranthus spinosus) 2020 .

28. Amin M, Malik U A, Sohail M. Mango fruit desapping in relation to time of harvest. Pakistan Journal of Botany. 2008;40(4):1587-1593.

29. Abu M. Quality Criteria for Mango Export in Ghana. Ph.D Thesis submitted to the School of Graduate Studies. Kwame Nkrumah University of Science and Technology, Kumasi: Ghana; 2010. p. 172.

30. Ambuko J, Kemunto N, Hutchinson M. (2017). Comparison of the Postharvest Characteristics of Mango Fruits Produced under Contrasting Agro- Ecological Conditions and Harvested at Different Maturity Stages. Journal of Agricultural Science. 2017;9.

31. AOAC. Official Methods of Analysis of AOAC INTERNATIONAL 18th Ed., AOAC INTERNATIONAL, Gaithersburg, MD, USA, Journal of the Association of Official Agricultural Chemists. 2005.

32. SAMGA. South Africa Mango Growers Association (SAMGA). Mango Internal Pulp Colour Chart. South Africa. 2004.

33. Snedecor GW, Cochran WG. Statistical Methods. The Iowa State University Press. 7th ed. Ames: Iowa; 1980. p. 507.

34. Karunanayake KOLC. A qualitative analysis of mango (Mangifera indica L.) latex and anatomy of latex canals. JSC EUSL. 2019;10(2):11-20.

35. Saby John K, Bhat S G, Prasada Rao UJS. Biochemical characterization of sap (latex) of a few Indian mango varieties. Phytochemistry. 2003;62(1):13-19.

36. Altendorf S. Mojor tropical fruits market review. Rome: FAO; 2019. p. 10 .

37. Tharanathan RN, Yashoda, HM, Prabha TN. Mango (Mangifera indicaL),"The King of Fruits"-An overview. Food reviews international. 2006;22:95-123. 